\title{
AVALIAÇÃO MICROBIOLÓGICA DE COXA E SOBRECOXA DE FRANGO COMERCIALIZADAS A GRANEL EM SINOP-MT
}

\section{MICROBIOLOGICAL EVALUATION OF THIGH AND DRUMSTICK CHICKEN SOLD IN BULK IN SINOP-MT}

\author{
Filipe Freitas ${ }^{1}$ ORCID - http://orcid.org/0000-0003-3747-1562 \\ Rodrigo de Almeida1 ORCID - http://orcid.org/0000-0001-6125-7158 \\ Jorge Luiz Fortuna ${ }^{2}$ ORCID - http://orcid.org/0000-0001-7996-837X \\ Claudius Couto Cabral ${ }^{3}$ ORCID - http://orcid.org/0000-0001-8115-6717 \\ Robson Maia Franco ${ }^{3}$ ORCID - http://orcid.org/0000-0003-0003-2961 \\ Thaís Badini Vieira ${ }^{*}$ ORCID - http://orcid.org/0000-0002-5206-6883

\footnotetext{
${ }^{1}$ Universidade Federal de Mato Grosso, Sinop, Mato Grosso, Brasil.

2 Universidade do Estado da Bahia, Teixeira de Freitas, Bahia, Brasil.

3 Universidade Federal Fluminense, Niterói, Rio de Janeiro, Brasil.

*Autora para correspondência - thais.badini@hotmail.com
}

\section{Resumo}

O consumo de carne de frango tem aumentado nos últimos anos, favorecido por diferentes fatores. No entanto, quando esse alimento é manipulado sem cuidados higiênicos pode ser fonte de agentes etiológicos causadores de enfermidades. O objetivo deste estudo foi avaliar a qualidade microbiológica de 60 amostras de carnes de frango industrial resfriadas in natura, coletadas de 20 estabelecimentos comerciais do município de Sinop - Mato Grosso. As avaliações microbiológicas foram compostas por: enumeração de coliformes totais e termotolerantes, pesquisa de Escherichia coli e identificação de Salmonella spp. Em 100\% das amostras foram encontrados coliformes totais. Seis amostras apresentaram valores de coliformes termotolerantes $>3 \mathrm{NMP} / \mathrm{g}$, porém não extrapolaram o padrão, $10^{4} \mathrm{NMP} / \mathrm{g}$, exigido pela legislação brasileira. Das 60 amostras avaliadas, $8,3 \%$ apresentaram contaminação por E. coli e 8,3\% estavam contaminadas por Salmonella spp. Em $30 \%$ dos mercados foram obtidas amostras contaminadas por E. coli (10\%) e Salmonella spp. (20\%), sendo consideradas impróprias para o consumo. Os sorovares de Salmonella spp. encontrados foram: Hadar, Minnesota, Heidelberg e Kentucky. Dessa forma, há a necessidade de que sejam aplicadas boas práticas de fabricação, higiene e manipulação de alimentos nos estabelecimentos a fim de reduzir a contaminação por microrganismos no produto final e os riscos para a saúde coletiva.

Palavras-chave: Cortes cárneos. Frango. Contaminação. Escherichia coli. Salmonella.

\begin{abstract}
The chicken meat consumption has increased in recent years favored by different factors. However, when this food is manipulated without hygienic care, can be a source of etiological agents that cause diseases. The objective of this study was to evaluate the microbiological quality of 60 samples of fresh chilled chicken meat cooled in nature, collected from 20 commercial establishments in the municipalyti of Sinop - Mato Grosso. The microbiological assessments were composed of: enumeration of total and thermotolerant coliforms, Escherichia coli research and identification of Salmonella spp. In $100 \%$ of the samples total coliforms were found. Six samples presented thermotolerant coliform values $>3 \mathrm{NMP} / \mathrm{g}$, but did not extrapolate the standard $10^{4} \mathrm{NMP} / \mathrm{g}$ required by brazilian legislation. Of the 60 samples evaluated, $8.3 \%$ presented contamination by $E$. coli and
\end{abstract}


$8.3 \%$ were contaminated by Salmonella spp.. In 30\% of markets were obtained contaminated samples by E. coli (10\%) and Salmonella spp. (20\%), being considered unsuitable for consumption.Theserovars of Salmonella spp. found were: Hadar, Minnesota, Heidelberg and Kentucky.In this way, there is a need for good manufacturing practices applied, hygiene and food handling in establishments in order to reduce contamination by microorganisms in the final product and the risks to collective health.

Key words: Meat cuts. Chicken. Contamination. Escherichia coli. Salmonella.

Recebido em 7 de novembro de 2017

Aceito em 3 de setembro de 2019

\section{Introdução}

O consumo e a produção de carne de frango têm aumentado nos últimos anos no país, alcançando 41,1 quilos per capita e 12,9 milhões de toneladas respectivamente, em 2016, tornando o Brasil o segundo maior produtor de carne de frango do mundo ${ }^{(1)}$. Projeções indicaram que a taxa de consumo continuará em ascensão constante a cada ano ${ }^{(2)}$. Diversos fatores favorecem o consumo desse alimento, sendo considerado saudável por conter ferro, vitaminas, proteínas de boa qualidade, pouca gordura e por ser adequado para todas as idades ${ }^{(3)}$.

No entanto, a carne de frango pode se tornar fonte de veiculação de microrganismos patogênicos quando produzida, manipulada ou armazenada sem os devidos cuidados higiênico-sanitários ${ }^{(4)}$. A ingestão de alimentos contaminados com patógenos, provenientes de manipulação e processamento inadequados, torna-se um dos riscos mais importantes à saúde coletiva ${ }^{(5)}$. Dentre os microrganismos patogênicos capazes de causar infecção alimentar destacam-se Escherichia coli e Salmonella spp., os quais, quando presentes no alimento e ingeridos, podem colonizar o intestino humano e alterar o funcionamento do trato gastrointestinal levando à ocorrência de enterites.

Desse modo, para que a carne de frango e os produtos derivados apresentem boa qualidade microbiológica e sejam inócuos para o consumidor, é necessário garantir que adequados padrões higiênico-sanitários durante a produção, processamento, manipulação e comercialização desses produtos sejam adotados ${ }^{(6)}$. Nesse contexto, as análises microbiológicas podem ser empregadas para investigar a contaminação por microrganismos indicadores, que permitem inferir se as condições higiênico-sanitárias da produção foram adequadas, assim como se o alimento em questão é inócuo para o consumo ${ }^{(7)}$.

Assim, considerando-se a cultura de consumo de carnes a granel na cidade de Sinop - MT e a falta de estudos sobre a qualidade desse produto disponível ao consumidor local, faz-se necessária a avaliação da qualidade microbiológica desse alimento, destinado ao consumo humano. Considerando o contexto exposto, o presente estudo foi elaborado de modo a avaliar a qualidade microbiológica de coxa e sobrecoxa de frango resfriadas, comercializadas a granel em mercados do município de Sinop - MT, mediante a enumeração de coliformes totais e termotolerantes, pesquisa de Escherichia coli, identificação de Salmonella spp. e sua sorotipificação.

\section{Material e métodos}

Para a realização desta pesquisa, foram adquiridas 60 amostras, contendo no mínimo 200 gramas, de 
coxa e sobrecoxa unidas e resfriadas, obtidas de frangos industriais e vendidas a granel em estabelecimentos comerciais no período de outubro de 2014 a abril de 2015. As amostras foram adquiridas em 20 estabelecimentos comerciais no município de Sinop - Mato Grosso, coletando-se simultaneamente três amostras embaladas separadamente no próprio estabelecimento comercial. Os exemplares foram acondicionados em caixa isotérmica com gelo reciclável e transportados ao Laboratório de Microbiologia Veterinária do Campus Universitário de Sinop para a realização de análises microbiológicas compostas por: enumeração de coliformes totais, coliformes termotolerantes, Escherichia coli e pesquisa de Salmonella spp. ${ }^{(8,9)}$.

Para a enumeração de coliformes totais e termotolerantes, foram utilizados 25 gramas da amostra, coletadas assepticamente, adicionando-as a $225 \mathrm{~mL}$ de água peptonada 0,1\% (ACUMEDIA ${ }^{\circledR}$, Michigan, EUA) e homogeneizada manualmente por 10 minutos. Em seguida, $1 \mathrm{~mL}$ desta solução foi transferida para um tubo contendo $9 \mathrm{~mL}$ de água peptonada $0,1 \%$, procedendo-se à diluição seriada até $10^{-3}$. A partir de cada diluição obtida foi transferido $1 \mathrm{~mL}$ para três séries de três tubos contendo $10 \mathrm{~mL}$ de Caldo Lauril Sulfato Triptose (LST) (KASVI ${ }^{\circledR}$, Paraná, Brasil), posteriormente incubados em estufa bacteriológica a $35^{\circ} \mathrm{C}$ durante 48 horas.

Após incubação, foram considerados positivos os tubos que estavam turvos e apresentavam gás no interior dos tubos de Durham. De cada tubo positivo foi transferida uma alíquota de alça bacteriológica para tubos contendo caldo Bile Verde Brilhante 2\% (VBBL 2\%) (HIMEDIA ${ }^{\circledR}$, Mumbai, Índia) e uma alçada para caldo Escherichia coli (EC) (HIMEDIA ${ }^{\circledR}$ ), sendo incubados respectivamente em estufa bacteriológica a $35^{\circ} \mathrm{C} / 48 \mathrm{~h}$ e em banho Maria a $44,5^{\circ} \mathrm{C} / 24 \mathrm{~h}$. Dos tubos positivos para VBBL 2\% e EC (turvos e com produção de gás no tubo de Durham) procedeu-se, respectivamente, o cálculo de número mais provável (NMP) de coliformes totais e termotolerantes.

A partir dos tubos de caldo EC positivos iniciou-se a identificação de E. coli, sendo semeada uma alíquota em placas contendo ágar "Eosyn Methylen Blue" (HIMEDIA $\left.{ }^{\circledR}\right)$. De cada placa foram selecionadas no mínimo cinco colônias com crescimento característico de $E$. coli para identificação bioquímica realizada em ágar "Triple Sugar Iron" (HIMEDIA ${ }^{\circledR}$ ), ágar Citrato de Simmons, ágar Sulfeto Indol Motilidade (SIM) (MICROMED $^{\circledR}$, Rio de Janeiro, Brasil) e Caldo MR-VP $\left(\right.$ HIMEDIA $^{\circledR}$ ) para a realização da prova do vermelho de metila e prova de Voges-Proskauer.

Para a identificação de Salmonella spp. foram utilizados 25 gramas de amostra homogeneizada em $225 \mathrm{~mL}$ de água peptonada tamponada 1\% (ACUMEDIA ${ }^{\circledR}$ ), incubada em estufa bacteriológica a 35 ${ }^{\circ} \mathrm{C}$ durante 18-20 horas. Após esse período procedeu-se à transferência de $0,1 \mathrm{~mL}$ de solução para tubo contendo $10 \mathrm{~mL}$ de caldo Rappaport-Vassiliadis (RV) (HIMEDIA ${ }^{\circledR}$ ) e 1,0 ml para tubo contendo $10 \mathrm{~mL}$ de caldo Selenito Cistina (CS) (HIMEDIA ${ }^{\circledR}$ ), sendo incubadas, respectivamente, em banho Maria a $41{ }^{\circ} \mathrm{C} / 24 \mathrm{~h}$ e em estufa bacteriológica a $35^{\circ} \mathrm{C} / 24 \mathrm{~h}$. Após incubação, alíquotas de ambos os tubos foram semeadas em placas contendo ágar Xilose Lisina Desoxicolato (XLD) (HIMEDIA ${ }^{\circledR}$ ), ágar Salmonella Shigella (SS) (HIMEDIA ${ }^{\circledR}$ ) e ágar Entérico Hektoen (HE) (HIMEDIA ${ }^{\circledR}$ ), incubados a $35^{\circ} \mathrm{C}$ por 24 horas.

A partir das placas que apresentaram crescimento característico de Salmonella spp., foram selecionadas cinco colônias para realização das provas bioquímicas compostas por: ágar "Triple Sugar Iron" (TSI) (HIMEDIA $\left.{ }^{\circledR}\right)$; ágar Lisina Ferro (LIA) (HIMEDIA ${ }^{\circledR}$ ); ágar Sulfeto Indol Motilidade (SIM) (MICROMED ${ }^{\circledR}$ ); caldo MR-VP (prova do vermelho de metila e Voges-Proskauer) $\left(\right.$ HIMEDIA $\left.^{\circledR}\right)$, ágar Citrato de Simmons $\left(\right.$ MICROMED $\left.^{\circledR}\right)$, ágar Ureia (HIMEDIA ${ }^{\circledR}$ ) e ágar Fenilalanina (MICROMED ${ }^{\circledR}$ ). As amostras com bioquímica característica para Salmonella spp. foram enviadas ao Laboratório de Controle Microbiológico de Produtos de Origem Animal da Universidade Federal Fluminense para realização de sorologia por aglutinação direta para a confirmação do gênero. 
As cepas foram plaqueadas em Ágar Nutriente e incubadas por 24 horas a $35^{\circ} \mathrm{C}$. Decorrido o tempo, foram submetidas ao teste de soroaglutinação utilizando soro polivalente somático contra Salmonella (PROBAC ${ }^{\circledR}$, São Paulo, Brasil). Todas as cepas que aglutinaram frente ao soro foram consideradas como pertencentes ao gênero Salmonella spp. As amostras com sorologia positiva foram encaminhadas para caracterização antigênica mediante a técnica de aglutinação com anti-soros poli e monovalentes, somáticos e flagelares no Laboratório Nacional de Referência Nacional de Enteroinfecções Bacterianas no Instituto Oswaldo Cruz, FIOCRUZ, RJ, Brasil. A comprovação do sorovar específico foi realizada e representada de acordo com a identificação de antígenos de superfície com antissoros somáticos e antígenos de flagelos com antissoros flagelares com antissoros flagelares seguindo o Esquema de Kauffman-White ${ }^{(10,11)}$.

\section{Discussões}

Os resultados da enumeração de coliformes totais e termotolerantes, identificação de Escherichia coli e pesquisa de Salmonella spp. estão representados na Tabela 1.

Tabela 1. Resultado das análises microbiológicas obtidas em triplicada de coxa e sobrecoxa de frango resfriadas, comercializadas no município de Sinop-Mato Grosso

\begin{tabular}{|c|c|c|c|c|c|c|c|c|}
\hline \multirow[t]{2}{*}{ Mercados } & \multicolumn{3}{|c|}{$\begin{array}{l}\text { Coliformes Totais } \\
\text { (NMP/g) }\end{array}$} & \multicolumn{3}{|c|}{$\begin{array}{c}\text { Coliformes } \\
\text { Termotolerantes } \\
\text { (NMP/g) }\end{array}$} & \multirow[t]{2}{*}{$\begin{array}{c}\text { Escherichia } \\
\text { coli }^{a}\end{array}$} & \multirow[t]{2}{*}{$\begin{array}{l}\text { Salmonella } \\
\text { spp. }{ }^{* \star * * / \mathbf{a}}\end{array}$} \\
\hline & Am. 1* $^{\star}$ & Am. 2 & Am. 3 & Am. 1 & Am. 2 & Am. 3 & & \\
\hline 1 & 93 & 43 & 23 & 9.2 & $<3$ & 9,2 & PRESENTE & Ausente \\
\hline 2 & 23 & 43 & 3.6 & $<3$ & $<3$ & $<3$ & Ausente & PRESENTE \\
\hline 3 & 15 & 150 & $>1.100$ & $<3$ & $<3$ & $<3$ & Ausente & Ausente \\
\hline 4 & 43 & 23 & 150 & $<3$ & $<3$ & $<3$ & Ausente & Ausente \\
\hline 5 & 93 & 38 & 93 & $<3$ & $<3$ & $<3$ & Ausente & PRESENTE \\
\hline 6 & $>1100$ & 460 & 210 & $<3$ & $<3$ & $<3$ & Ausente & Ausente \\
\hline 7 & 43 & 43 & 93 & 43 & 23 & 93 & PRESENTE & Ausente \\
\hline 8 & 9,2 & 23 & 43 & 3.6 & $<3$ & 3,6 & Ausente & Ausente \\
\hline 9 & 23 & 43 & 43 & $<3$ & $<3$ & $<3$ & Ausente & Ausente \\
\hline 10 & $<3$ & 3.6 & $<3$ & $<3$ & $<3$ & $<3$ & Ausente & Ausente \\
\hline 11 & 43 & 460 & 43 & $<3$ & $<3$ & $<3$ & Ausente & PRESENTE \\
\hline 12 & 43 & 460 & 240 & 9.2 & 28 & 3.6 & Ausente & PRESENTE \\
\hline 13 & 23 & $<3$ & $<3$ & $<3$ & $<3$ & $<3$ & Ausente & Ausente \\
\hline 14 & $>1100$ & $>1.100$ & $>1.100$ & $<3$ & $<3$ & $<3$ & Ausente & Ausente \\
\hline 15 & 9.2 & 75 & 23 & $<3$ & $<3$ & $<3$ & Ausente & Ausente \\
\hline 16 & 3.6 & 9.2 & 23 & $<3$ & $<3$ & $<3$ & Ausente & Ausente \\
\hline 17 & $<3$ & 9.2 & 93 & $<3$ & $<3$ & $<3$ & Ausente & Ausente \\
\hline 18 & 150 & 93 & 43 & 3,6 & $<3$ & $<3$ & Ausente & Ausente \\
\hline 19 & 23 & 93 & 9.2 & 9.2 & 3.0 & 3.6 & Ausente & Ausente \\
\hline 20 & 38 & 460 & 210 & $<3$ & $<3$ & $<3$ & Ausente & Ausente \\
\hline Padrão**ं* & \multicolumn{3}{|c|}{ NÃO HÁ } & \multicolumn{3}{|c|}{$1,0 \times 10^{4}$} & $\dot{*} * \dot{*}$ & NÃO HÁ \\
\hline
\end{tabular}


Todas as amostras $(100 \%)$ apresentaram contaminação por coliformes totais em relação à avaliação do número mais provável por grama $(\mathrm{NMP} / \mathrm{g})$. Dos resultados obtidos para coliformes termotolerantes, as amostras provenientes de seis supermercados (30\%) tiveram valores superiores a $3 \mathrm{NMP} / \mathrm{g}$. Dos 20 estabelecimentos pesquisados, em dois foram obtidas amostras contaminadas com E. coli e, em outros quatro, amostras contaminadas com Salmonella spp.

Nos mercados 2, 5, 11 e 12, foram identificados, respectivamente: Salmonella Hadar e Salmonella enterica subspécie enterica (O: 6,8e colônia rugosa); Salmonella Minnesota e Salmonella enterica subspécie entérica (O: 6,8); Salmonella Heidelberg; Salmonella enterica subspécie enterica (O: 6,8e colônia rugosa) e Salmonella Kentucky.

Penteado et al. ${ }^{(12)}$, ao analisarem diferentes cortes de frango (coxa, frango a passarinho, sobrecoxa e asa), encontraram $100 \%$ das amostras de carne de frango contaminadas por coliformes totais, todavia nenhuma apresentou contagem superior a $410 \mathrm{NMP} / \mathrm{g}$. Beraldo-Massoli et al. ${ }^{(13)}$, ao pesquisarem coliformes totais em coração, coxa e peito de frango, identificaram a presença de coliformes totais em $88,8 \%(16 / 18)$ das amostras, sendo duas de coxa $(3,70 \%)$ e uma de coração $(1,85 \%)$ com valores superiores $1,1 \times 10^{3} \mathrm{NMP} / \mathrm{g}$. No presente estudo, além de os coliformes totais terem sido identificados em todas as amostras, em 8,33\% (5/60) das amostras provenientes de três mercados diferentes foram obtidas contagens superiores a $1,1 \times 10^{3} \mathrm{NMP} / \mathrm{g}$, contendo, portanto, mais microrganismos quando comparados aos encontrados por outros pesquisadores.

Embora a legislação brasileira não estabeleça parâmetros para coliformes totais em carne de frango in natura, estes microrganismos são importantes de serem avaliados em produtos destinados ao consumo humano, visto que permitem inferir sobre sua qualidade de processamento, armazenamento, distribuição para consumo, sua vida de prateleira e os potenciais riscos para a saúde pública ${ }^{(5)}$. Nesse contexto, a pesquisa de coliformes pode fornecer informações sobre as condições higiênico-sanitárias as quais o alimento foi submetido.

O grupo dos coliformes é composto pelos gêneros Citrobacter, Enterobacter, Klebsiella e Escherichia ${ }^{(7)}$. De acordo com a temperatura de fermentação da lactose com produção de gás, este grupo pode ser dividido em dois: os coliformes totais e os termotolerantes. A identificação de coliformes totais em água e alimentos não necessariamente irá indicar contaminação fecal uma vez que esse grupo de bactérias não possui origem exclusivamente entérica. Dessa forma, as amostras analisadas nesse estudo podem ter sido contaminadas devido a práticas inadequadas de manipulação, armazenamento incorreto e acondicionamento indevido do alimento in natura em embalagens contaminadas ${ }^{(14)}$.

Em relação aos coliformes termotolerantes, a identificação desse grupo de microrganismos nos alimentos pode ser interpretada como indicador de contaminação fecal visto que a esse grupo pertencem as estirpes de Escherichia coli e essas bactérias têm origem exclusiva no trato intestinal de homens e animais ${ }^{(5)}$. Cepas de E. coli podem contaminar os alimentos a partir de manipuladores infectados, da água contaminada por matéria fecal humana ${ }^{(14)}$, de embalagens, equipamentos e utensílios mal higienizados ${ }^{(15)}$.

No presente estudo, o valor máximo obtido para coliformes termotolerantes foi de $93 \mathrm{NMP} / \mathrm{g}$ e $76,6 \%$ $(46 / 60)$ das amostras apresentaram NMP/g $<3$. Em pesquisa semelhante, Beraldo-Massoli et al. ${ }^{(13)} \mathrm{e}$ Penteado et al. ${ }^{(12)}$ encontraram valores de coliformes termotolerantes $>10^{4} \mathrm{NMP} / \mathrm{g}$ em $55 \%(10 / 18) \mathrm{e}$ entre $0,31 \mathrm{NMP} / \mathrm{g}$ a $655 \mathrm{NMP} / \mathrm{g}$ em $100 \%$ das amostras, respectivamente. Em relação a esse grupo de microrganismos, a Agência Nacional de Vigilância Sanitária (ANVISA), na Resolução da Diretoria Colegiada RDC $\mathrm{n}^{\circ} 12$, de 2 de janeiro de $2001^{(16)}$, define que carnes de aves resfriadas in natura 
(carcaça inteira, fracionada ou cortes) devem possuir valor máximo de $10^{4} \mathrm{NMP} / \mathrm{g}$. Assim, considerando o valor máximo obtido no presente estudo, pode-se afirmar que todas as amostras analisadas estavam dentro do padrão permitido pela legislação brasileira para coliformes termotolerantes.

A partir das análises para coliformes termotolerantes, foram identificadas estirpes de $E$. coli em cinco amostras (5/60) provenientes de dois supermercados. Apesar de a legislação brasileira não estabelecer parâmetros para E. coli em carne de aves resfriadas, há a exigência de um laudo analítico se essa bactéria for identificada. Essa exigência pode estar relacionada ao fato de que a presença de E. coli no alimento pode representar risco à saúde coletiva, visto que algumas linhagens possuem potencial patogênico e são consideradas agentes causadores de gastroenterites em humanos ${ }^{(7,14)}$.

Assim, apesar de todas as amostras estarem dentro dos parâmetros estabelecidos pela legislação quanto ao $\mathrm{NMP} / \mathrm{g}$ de coliformes termotolerantes, as amostras em que foram isoladas $E$. coli devem ser consideradas impróprias para consumo por conterem agentes etiológicos que poderiam causar enfermidades em humanos.

Embora muitos trabalhos relatem ausência de Salmonella spp. em carne de frango ${ }^{(12,13,17,18)}$, Tirolli e Costa ${ }^{(19)}$ e Tessari et al. ${ }^{(20)}$ identificaram, respectivamente, 50\% (30/60) e 2,5\% (3/116) das carcaças de frango analisadas contaminadas com essa bactéria. Na atual pesquisa, 8,3\% das amostras (5/60) oriundas de quatro mercados estavam contaminadas com Salmonella spp.

Bactérias do gênero Salmonella possuem como habitat o trato intestinal de seres humanos e outros animais, principalmente aves. Esses microrganismos possuem sorovares que são patogênicos para os seres humanos, podendo ser veiculados ao homem pelo consumo de alimentos contaminados, provocando infecções alimentares que levam à diarreia, febre e cólicas abdominais ${ }^{(14)}$.

A presença dessa bactéria em frangos pode estar associada à forma de transporte desses animais em que são mantidos aglomerados, aumentando o risco de infecção por Salmonella spp. Além disso, o abate e o processamento das carcaças também podem contribuir para a disseminação e multiplicação desses microrganismos na carne de frango por meio de operações de abate inapropriadas, contaminação cruzada de equipamentos e utensílios ${ }^{(19)}$. Ademais, o manuseio inadequado durante a evisceração, cortes e acondicionamento podem favorecer à dispersão dessas bactérias ${ }^{(19)}$. Somandose a isso, manipuladores que não possuam hábitos de higiene adequados também podem contaminar os cortes de frango ou promover contaminação cruzada no estabelecimento ${ }^{(7,14)}$. Assim, os produtos avícolas, principalmente carne de frango, elaborados ou conservados de forma deficiente, podem servir como veículo de Salmonella para seres humanos, levando a surtos de infecções alimentares ${ }^{(21)}$.

Neste estudo, em quatro mercados foram identificadas Salmonella enterica subspécie enterica a qual tem como "habitat" os animais de sangue quente e são responsáveis pela maioria das salmoneloses humanas ${ }^{(22)}$. O sorovar Enteritidis tem sido identificado frequentemente em carcaças de frangos ${ }^{(23,}$ ${ }^{24,25)}$ e é o mais comum em infecções em seres humanos ${ }^{(26)}$. Contudo, essa estirpe não foi encontrada na atual pesquisa.

Nos quatro mercados foram obtidos diferentes sorovares como Salmonella Hadar; Minnesota; Heidelberg e Kentucky, havendo, portanto, uma diversidade de subtipos bacterianos encontrada nos estabelecimentos pesquisados. Essa diversidade poderia estar relacionada à cadeia de produção de frango comercializado ao mercado, ou ainda, à manipulação e/ou armazenamento incorreto no estabelecimento. 
Torna-se importante destacar a presença de dois sorovares devido ao aumento de ocorrência no Brasil: Heidelberg, o qual foi o sorovar de maior prevalência identificado no sul do Brasil ${ }^{(27,28,29)}$, e sorovar Minnesota, que tem sido considerado emergente na avicultura ${ }^{(30)}$ e vem ganhando destaque devido à identificação desse sorovar nos plantéis e em produtos avícolas ${ }^{(31)}$. Embora os animais infectados não apresentem sinais clínicos ou perda de desempenho, a Salmonella Minnesota possui uma grande relevância para a saúde coletiva, visto que são potencialmente patogênicos para humanos ${ }^{(31,32)}$.

Na legislação brasileira, a Resolução da Diretoria Colegiada RDC n ${ }^{\circ} 12$, de 2 de janeiro de $2001^{(16)}$, estabeleceu que "Salmonella deve estar ausente em $25 \mathrm{~g}$ de carnes resfriadas, ou congeladas, in natura, de bovinos, suínos e outros mamíferos (carcaças inteiras ou fracionadas, quartos ou cortes), carnes moídas; miúdos de bovinos, suínos e outros mamíferos, ovos e derivados”, porém não incluiu neste contexto as carnes de aves resfriadas in natura (carcaça inteira, fracionada ou cortes). Entretanto, a ANVISA, através da RDC No 13 , de 2 de janeiro de $2001{ }^{(33)}$, instituiu o Regulamento técnico com instruções de uso, preparo e conservação na rotulagem de carnes de aves e seus miúdos crus, resfriados ou congelados, com exigências que visam a reduzir os riscos à saúde do consumidor pela presença de Salmonella spp. nesses alimentos.

Desse modo, considerando que a presença de Salmonella significa risco à saúde da população caso o produto não seja adequadamente conservado e preparado, as amostras em que foram isoladas essas bactérias devem ser consideradas impróprias para consumo por serem veiculadores de patógenos causadores de gastroenterites.

Importante ressaltar que $30 \%$ dos mercados analisados estavam comercializando alimentos impróprios para o consumo, visto que $20 \%$ apresentaram contaminação por Salmonella spp. enquanto os outros $10 \%$ com contaminação por cepas de E. coli, as quais possuem potencial patogênico.

Assim, tendo em vista os riscos para saúde coletiva relacionada ao consumo de alimentos contaminados com agentes causadores de enfermidades em humanos, fica evidente a necessidade de que sejam aplicadas boas práticas de fabricação, higiene e manipulação ao longo de toda a cadeia produtiva a fim de reduzir a contaminação no produto final.

\section{Conclusão}

Todas as amostras apresentaram enumeração de coliformes termotolerantes menor que $10^{4} \mathrm{NMP} / \mathrm{g}$ exigida pela legislação vigente. Em 30\% dos mercados foram obtidas amostras contaminadas e consideradas impróprias para o consumo pela presença de Escherichia coli (10\%) e Salmonella spp. $(20 \%)$.

\section{Referências}

1. ABPA (Associação Brasileira de Proteína Animal). Relatório Anual ABPA 2017 [Internet]. São Paulo: Associação Brasileira de Proteína Animal; 2017 [cited 2017 Ago 15]. Available from: http://abpabr.com.br/setores/avicultura/publicacoes/relatorios-anuais. Portuguese.

2. Brasil. Projeções do Agronegócio - Brasil 2015/2016 a 2025/2026. Brasília: Ministério da Agricultura, Pecuária e Abastecimento; 2017. [cited 2017 Ago 15]. Available 
from:http://www.agricultura.gov.br/assuntos/politica-agricola/todas-publicacoes-de-politicaagricola/projecoes-do-agronegocio/proj_agronegocio2016.pdf/view. Portuguese.

3. Venturini KS, Sarcinelli MF, Silva LC. Características da carne de frango. Universidade Federal do Espírito Santo - UFES, Boletim Técnico, 2007.

4. Freitas MFL, Mota RA, Vilela SM, Sena MJ, Bezerra R. Cepas de Staphylococcus spp. isoladas de carcaça de frango comercializadas na cidade de Recife - PE, Brasil. Ciência Animal Brasileira. 2001;2(2):139-145.

5. Franco BDGM, Landgraf M. Microbiologia dos Alimentos. $1^{a}$ ed. São Paulo: Atheneu; 2008. 182p. Portuguese.

6. Souza GC, Gonsalves HRO, Gonsalves HEO, Coêlho JLS. Característica microbiológica da carne de frango. ACSA - Agropecuária Científica no Semiárido. 2014;10(2):12-17.

7. Jay JM. Microbiologia de Alimentos. $6^{\mathrm{a}}$ ed. Porto Alegre: Artmed; 2005. 711p. Portuguese.

8. Brasil. Ministério da Agricultura, Pecuária e Abastecimento. Instrução Normativa ${ }^{\circ} 62$ de 26 de Agosto de 2003. Oficializa os Métodos Analíticos Oficiais para Análises Microbiológicas para Controle de Produtos de Origem Animal e Água. Diário Oficial da União. 2003 Set 18; Seção 1. Portuguese.

9. Blodgett R. Bacteriological Analytical Manual. [Internet] U.S. Department of Health and Human Services; 2010 Oct. $\quad$ [cited $2017 \quad$ Ago 15$] \quad$ Available from:http://www.fda.gov/Food/FoodScienceResearch/LaboratoryMethods/ucm109656.htm.

10. Grimont PAD, Weill FX. Antigenic formulae of Salmonella serovars. WHO Collaborating Centre for Reference and Research on Salmonella, $9^{\mathrm{a}}$ ed. France: Institute Pasteur; 2007. 167p.

11. Guibourdenche M, Roggentin P, Mikoleit M, Fields PI, Bockemuhl J, Grimont, PAD, Weill FX. Supplement 2003-2007 (No.47) to the White-Kauffmann-Le Minor scheme. Res. Microbiol. 2010;161:26-29.

12. Penteado FR, Esmerino LA. Avaliação da qualidade microbiológica da carne de frango comercializada no município de Ponta Grossa - Paraná. Publ. UEPG Biol. Health Sci. 2011;17(1):37-45.

13. Beraldo-Massoli MC, Cardoso MV, Cavani C, Gomes MOS, Shocken-Iturrino RP. Qualidade microbiológica de frango comercializado na cidade de Jaboticabal, São Paulo. Investigação. 2013;13:24-28.

14. Franco R M. Agentes Etiológicos de Doenças Alimentares. 1ª ed. Niterói: Editora UFF; 2012. 119 p. Portuguese.

15. Rezende C, Seemann CF, Sivla ES, Jacobucci HB, Mattar M. Superfície inanimada - possível fonte de contaminação microbiológica no alimento. Revista Brasileira de Farmácia. 2012;93(4):444-449.

16. BRASIL. Agência Nacional de Vigilância Sanitária. Resolução RDC n ${ }^{0} 12$ de 02 de Janeiro de 2001. Regulamento Técnico Sobre Padrões Microbiológicos para Alimentos. Diário Oficial da União, 2001 Jan 10; Seção 1. Portuguese.

17. Cardoso ALSP, Tessari ENC, Castro AGM, Kanashiron AMI. Pesquisa de Salmonella sp., coliformes totais, coliformes fecais e mesófilos em carcaças e produto derivados de frango. Arq. Inst. Biol. 2000;67(1):2530.

18. Silva KRC, Menão MC. Avaliação microbiológica de cortes de frango comercializados na idade de São Paulo. Atas de Saúde Ambiental - ASA. 2015;3(2):17-23.

19. Tirolli ICC, Costa CA. Ocorrência de Salmonella spp. em carcaças de frango recém abatidos em feiras e mercados de Manaus - AM. ACTA AMAZONICA. 2006;36(2):205-208.

20. Tessari ENC, Cardoso ALSP, Kanashiro AMI, Stoppa GFZ, Luciano RL, Castro AGM. Ocorrência de Salmonella spp. em carcaças de frango industrialmente processadas, procedente de exploração industriais do Estado de São Paulo, Brasil. Ciência Rural. 2008;38(9):2557-2560.

21. Mendonça EP, Melo RT, Nalevaiko PC, Monteiro GP, Fonseca BB, Galvão NN, Giombelli A, Rossi DA. 
Spread of the serotypes and antimicrobial resistance in strains of Salmonella spp. isolated from broiler. Brazilian Journal of Microbiology. 2019;50(2):515-522.

22. Silva N, Junqueira VCA, Silveira NFA, Taniwaki MH, Santos RFS, Gomes RAR. Salmonella. In: Manual de métodos de análise microbiológica de alimentos. $4^{\mathrm{a}}$ ed. São Paulo: Livraria Varela; 2010. p. 287-320.

23. Rezende CSM, Mesquita AJ, Andrade MA, Linhares GFC, Mesquita AQ, Minafra CS. Sorovares de Salmonella isolados de carcaças de frangos de corte abatidos no Estado de Goiás, Brasil, e perfil de resistência a antimicrobianos. RPCV. 2005;100(555-556):199-203.

24. Alcocer I, Oliveira KMP, Vidotto MC, Oliveira TCRM. Discriminação de sorovares de Salmonella spp. isolados de carcaças de frango por rep e eric-pcr e fagotipagem do sorovar enteritidis. Ciênc. Tecnol. Aliment. 2006;26(2):414-420.

25. Cardoso ALSP, Kanashiro AMI, Stoppa GFZ, Castro AGM, Luciano RL, Tessari ENC. Ocorrência de Salmonella spp. em carcaças de frango provenientes de abatedouros do estado de São Paulo, Brasil, no período de 2000 a 2010. Revista Científica de Medicina Veterinária. 2015;24(1).

26. Kottwitz LBM, Oliveira TCRM, Alcocer I, Farah SMSS, Abrahão WSM, Rodrigues DP. Avaliação epidemiológica de surtos de salmonelose ocorridos no período de 1999 a 2008 no Estado do Paraná, Brasil. Acta Scientiarum. Health Sciences. 2010;32(1):9-15.

27. Cardoso ALSP, Tessari ENC. Salmoneloses aviárias: Revisão. Revista Eletrônica Nutritime [Internet]. 2015 Mai/Jun [cited 2017 Ago 15];12(3):4049-4069. Available from: http://nutritime.com.br/arquivos_internos/artigos/ARTIGO304a.pdf. Portuguese.

28. Pandini JA, Pinto FGS, Muller JM, Weber LD, Moura AC. Ocorrência e perfil de resistência antimicrobiana de sorotipos de Salmonella spp. isolados de aviários do Paraná, Brasil. Arq. Inst. Biol. 2015;82:1-6.

29. Saúde Animal. Salmonella Heidelberg é líder absoluta entre variantes no Sul do país [Internet]. O Presente Rural; 2016 Ago 08 [cited 2017 Ago 15]. Available from: http://opresenterural.com.br/noticia/salmonellaheidelberg-e-lider-absoluta-entre-variantes-no-sul-do-pais/8105/. Portuguese.

30. Santos JR, Meza SKL, Martini KC, Nunes RV. A importância do controle da Salmonella na cadeia produtiva de frango de corte. Scientia Agraria Paranaensis. 2013;12(3):167-174.

31. Resende AR. Fatores de patogenicidade e estudo epidemiológico de Salmonella Minnesota de origem avícola. 2015. 67 f. Tese (Mestrado em Ciências Veterinárias) - Programa de Pós-Graduação em Ciências Veterinárias, Universidade Federal de Uberlândia, Uberlândia. 2015. Available from:https://sucupira.capes.gov.br/sucupira/public/consultas/coleta/trabalhoConclusao/viewTrabalhoConclus ao.jsf?popup=true\&id trabalho $=2795447$. Portuguese.

32. Saúde Animal. Bacillus subtilis controla salmonela [Internet]. Avicultura Industrial; 2011 Nov 18 [cited 2017 Ago 15]. Available from:

https://www.aviculturaindustrial.com.br/imprensa/bacillus-subtilis-controla-salmonela/20111118-083330w768. Portuguese.

33. BRASIL. Agência Nacional de Vigilância Sanitária. Resolução RDC n 13 de 02 de Janeiro de 2001. Regulamento técnico para instruções de uso, preparo e conservação na rotulagem de carne de aves e seus miúdos crus, resfriados ou congelados. Diário Oficial da União, 2001 Jan 10; Seção 1. Portuguese. 